\title{
Rational design of perfectly oriented thermally activated delayed fluorescence emitter for efficient red electroluminescence
}

\author{
Xuan Zeng ${ }^{1,2 \dagger}$, Yu-Hsin Huang ${ }^{3 \dagger}$, Shaolong Gong ${ }^{1 *}$, Xuguang Yin ${ }^{1}$, Wei-Kai Lee ${ }^{3}$, Xiao Xiao ${ }^{1}$, \\ Yu Zhang, Weixuan Zeng ${ }^{1}$, Chen-Han Lu ${ }^{3}$, Chang-Cheng Lee ${ }^{3}$, Xiu-Qin Dong ${ }^{1}$, Cheng Zhong ${ }^{1}$, \\ Chung-Chih $\mathrm{Wu}^{3^{*}}$ and Chuluo Yang ${ }^{1,2^{*}}$
}

\begin{abstract}
How to control the dipole orientation of organic emitters is a challenge in the field of organic light-emitting diodes (OLEDs). Herein, a linear thermally activated delayed fluorescence (TADF) molecule, PhNAI-PMSBA, bearing a 1,8naphthalimide-acridine framework was designed by a doublesite long-axis extension strategy to actively control the dipole orientation. The horizontal ratio of emitting dipole orientation of PhNAI-PMSBA reaches 95\%, substantially higher than that of isotropic emitters (67\%). This unique feature is associated with the intrinsically horizontal molecular orientation of PhNAI-PMSBA and the good agreement between its transition dipole moment direction and molecular long axis. The PhNAI-PMSBA-based OLED achieves an ultrahigh optical outcoupling efficiency of $43.2 \%$ and thus affords one of the highest red electroluminescence with an external quantum efficiency of $22.3 \%$ and the Commission International de l'Eclairage 1931 coordinates at around $(0.60,0.40)$.
\end{abstract}

Keywords: organic light-emitting diodes, thermally activated delayed fluorescence, dipole orientation, outcoupling efficiency

\section{INTRODUCTION}

Controlling and tuning the molecular orientation of organic functional materials is an attractive issue in the field of organic light-emitting diodes (OLEDs), because the molecular orientation greatly affects the optical and electrical properties, such as refractive index, carrier transportation and light extraction [1-4]. Especially for organic emitters used in OLEDs, the horizontal molecular orientation usually benefits horizontal emitting dipole orientation (EDO). Accordingly, the theoretical limit of optical outcoupling efficiency $\left(\Phi_{\text {out }}\right)$ for OLEDs can be boosted from nearly $30 \%$ for isotropic emitters to $~ 45 \%$ for fully horizontal emitters [5-8]. Therefore, the control of molecular orientation has been regarded as a promising method in developing excellent organic emitters towards ultrahigh-efficiency OLEDs. The molecular orientation of organic emitters is generally influenced by various factors, including molecular structure, substrate temperature and host-guest interactions [3,9-11]. Up to now, a number of empirical trends are demonstrated in the emitter design to achieve preferentially horizontal molecular orientation and EDO. Moreover, the underlying mechanism about the effect of molecular structure on dipole orientation is still unclear [12-14]. The control of the dipole orientation of organic emitters is challenging.

In the past decade, thermally activated delayed fluorescence (TADF) emitters are particularly attractive in OLEDs because of their merits in harvesting triplet excitons without using noble metals [15-19]. To further boost device performance of TADF OLEDs, many efforts have been made to control the EDO of TADF emitters [20-22]. In virtue of variable molecular structures, TADF emitters' molecular conformation can be easily altered to linear or planar shape, leading to favorable anisotropic

\footnotetext{
${ }^{1}$ Renmin Hospital of Wuhan University, Department of Chemistry, Hubei Key Lab on Organic and Polymeric Optoelectronic Materials, Wuhan University, Wuhan 430072

${ }^{2}$ College of Materials Science and Engineering, Shenzhen University, Shenzhen 518060

${ }^{3}$ Department of Electrical Engineering, Graduate Institute of Electronics Engineering and Graduate Institute of Photonics and Optoelectronics, Taiwan University, Taipei 10617

† These authors contributed equally to this work.

* Corresponding authors (emails: slgong@whu.edu.cn (Gong S); wucc@ntu.edu.tw (Wu CC); clyang@whu.edu.cn (Yang C))
} 
orientation [23-26]. To design excellent TADF emitters, the rigid molecular structure to suppress non-radiative processes and the suitable separation of frontier molecular orbital (FMO) distribution to guarantee effective reverse intersystem crossing (RISC) process should also be taken into consideration when modulating molecular shape [27-31]. In this context, some TADF emitters have been developed to exhibit preferentially horizontal dipole orientation [22,32,33]. For example, Komino et al. [34] reported a fully horizontal oriented TADF emitter at the optimized deposition temperature and in host matrixes. Despite these efforts, the TADF emitters with a nearperfect horizontal dipole ratio $\left(\Theta_{\|}\right)$were rare.

Therefore, further work is highly required to construct TADF emitters with high $\Theta_{/ /}$and gain a deeper understanding of the underlying mechanism behind the preferentially horizontal dipole orientation. In this study, a linear TADF emitter, 2-(4'-(tert-butyl)-[1,1'-biphenyl]-4yl)-6-(10'-(4'-(tert-butyl)-[1,1'-biphenyl]-4-yl)-2,7-dimethyl-10H,10'H-9,9'-spirobi[acridi]-10-yl)- $1 H$-benzo [de] isoquinoline-1,3(2H)-dione (PhNAI-PMSBA), was constructed using a double-site long-axis extension strategy (Fig. 1). Within this strategy, based on a rigid 1,8naphthalimide-acridine (NAI-AC) hybrid framework, two tert-butylbiphenyl units were selectively introduced into the 1,8-naphthalimide (NAI) and acridine (AC) moieties to elongate the molecular long axis. The methyl groups in AC units not only enhanced the intramolecular charge transfer (ICT) transition between the NAI and AC units, but also afforded the suitable separation of FMO distribution of PhNAI-PMSBA. A reference emitter, 2(4'-(tert-butyl)-[1,1'-biphenyl]-4-yl)-6-(2,7-dimethyl$10 H$-spiro[acridine-9,9'-fluoren]-10-yl)- $1 H$-benzo[de]isoquinoline-1,3(2H)-dione (PhNAI-MFAC), was synthesized by incorporating only one tert-butylbiphenyl unit into the NAI moiety for comparison. As expected, both emitters exhibited red emissions with distinct TADF nature in both solution and doped films. Moreover, PhNAI-PMSBA had a linear molecular shape in a $35.7 \AA$ length verified by the single-crystal structure. Inspiringly, PhNAI-PMSBA exhibited a high $\Theta_{/ /}$of $95 \%$ in the host matrix, which is among the best value for horizontally oriented emitters. The molecular dynamics (MD) simulations and optical studies revealed that the underlying
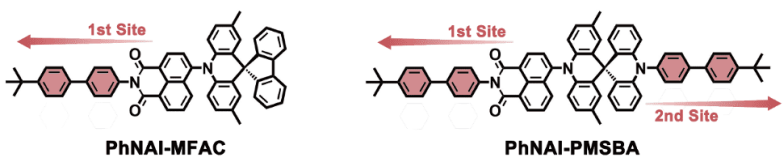

Figure 1 Molecular structures of PhNAI-MFAC and PhNAI-PMSBA. mechanism of such high $\Theta_{\| /}$was related to the intrinsically horizontal molecular orientation of PhNAIPMSBA in the host matrix and the good consistence between the transition dipole moment (TDM) direction and the molecular long axis of PhNAI-PMSBA. Benefitting from the high $\Theta_{/ /}$, the resulting OLED based on PhNAI-PMSBA achieved an ultrahigh $\Phi_{\text {out }}$ of $43.2 \%$, far exceeding the theoretical limit of nearly $30 \% \Phi_{\text {out }}$ for isotropic emitters. Finally, a high external quantum efficiency $\left(\eta_{\text {ext }}\right)$ of over $22 \%$ was demonstrated for the PhNAI-PMSBA-based OLED, accompanied with a red emission and favorable Commission International de l'Eclairage 1931 (CIE1931) coordinates located at around $(0.60,0.40)$.

\section{EXPERIMENTAL SECTION}

\section{Synthesis}

The synthetic routes of the intermediates of 2-bromo- $N$ (4-methoxybenzyl)-4-methyl-N-( $p$-tolyl)aniline (PMBDPA) and 6-bromo-2-(4'-(tert-butyl)-[1,1'-biphenyl]-4-yl)-1H-benzo[de] isoquinoline-1,3(2H)-dione (BrPhNAI) were provided in supplementary information. All reagents were used as received from commercial sources unless otherwise stated. Standard procedures were used to dry the solvents.

Synthesis of 10-(4-Methoxybenzyl)-2,7-dimethyl-10H, $10^{\prime} H-9,9^{\prime}$-spirobi[acridine] (A). $\quad n$-BuLi $\quad\left(2.3 \mathrm{~mol} \mathrm{~L}^{-1}\right.$, $1.74 \mathrm{~mL}, 4.0 \mathrm{mmol}$ ) in hexane was dropwise added to a solution of PMBDPA $(1.58 \mathrm{~g}, 4.0 \mathrm{mmol})$ in tetrahydrofuran (THF) $(15 \mathrm{~mL})$ at $-78^{\circ} \mathrm{C}$ under argon atmosphere. After stirring at $-78^{\circ} \mathrm{C}$ for $2 \mathrm{~h}, 10-((2-$ methoxyethoxy)methyl)acridin-9(10H)-one (1.25 g, $4.4 \mathrm{mmol})$ in THF $(10 \mathrm{~mL})$ was dropwise added. The mixture was stirred at $-78^{\circ} \mathrm{C}$ for another $2 \mathrm{~h}$, gradually warmed to room temperature, and then acidified with diluted $\mathrm{HCl}\left(0.5 \mathrm{~mol} \mathrm{~L}^{-1}, 10.0 \mathrm{~mL}\right)$ overnight. After stirring for one day, the reaction mixture was treated with aqueous $\mathrm{K}_{2} \mathrm{CO}_{3}$, extracted with dichloromethane, washed with brine, and dried over anhydrous $\mathrm{Na}_{2} \mathrm{SO}_{4}$. After removal of the solvent, the crude product was purified by column chromatography on silica gel with petroleum ether/dichloromethane (2:1 by vol.) as the eluent. Finally, the product was obtained as a white powder, $1.49 \mathrm{~g}$, yield: $75 \%$. Melting point $(\mathrm{Mp}): \quad 244-247^{\circ} \mathrm{C} .{ }^{1} \mathrm{H}$ NMR $\left(400 \mathrm{MHz}, \mathrm{CD}_{2} \mathrm{Cl}_{2}\right) \delta$ (ppm): $7.24(\mathrm{~d}, J=8 \mathrm{~Hz}, 2 \mathrm{H}), 7.04$ $(\mathrm{t}, J=8 \mathrm{~Hz}, 2 \mathrm{H}), 6.93-6.91(\mathrm{~m}, 4 \mathrm{H}), 6.81-6.76(\mathrm{~m}, 4 \mathrm{H})$, 6.72-6.66 (m, 6H), $6.38(\mathrm{br}, 0.9 \mathrm{H}), 5.16(\mathrm{~s}, 2 \mathrm{H}), 3.79(\mathrm{~s}$, $3 \mathrm{H}), 2.03(\mathrm{~s}, 6 \mathrm{H}) .{ }^{13} \mathrm{C} \mathrm{NMR}\left(100 \mathrm{MHz}, \mathrm{CD}_{2} \mathrm{Cl}_{2}\right) \delta(\mathrm{ppm})$ : $160.7,138.1,137.6,134.8,134.5,134.0,132.7,131.4,131.1$, 
$129.8,129.1,128.9,122.5,116.1,115.3,114.5,57.2,52.2$, 48.9, 22.1. High resolution mass spectrum (HRMS, ESI): $m / z[\mathrm{M}+\mathrm{H}]^{+}$calcd. for $\mathrm{C}_{35} \mathrm{H}_{31} \mathrm{~N}_{2} \mathrm{O}^{+}:$495.2431; found: 495.2427.

Synthesis of $10^{\prime}$-(4'-(tert-butyl)-[1,1'-biphenyl]-4-yl)10-(4-methoxybenzyl)-2,7-dimethyl-10H,10' H-9,9'-spirobi[acridine] (B). 4-Bromo-4'-(tert-butyl)-1,1'-biphenyl (864 mg, $3.0 \mathrm{mmol})$, compound A $(1.24 \mathrm{~g}, 2.5 \mathrm{mmol})$, sodium tert-butoxide $(288 \mathrm{mg}, 3.0 \mathrm{mmol})$, palladium(II) acetate $(20 \mathrm{mg}, \quad 0.09 \mathrm{mmol})$ and tri-tert-butylphosphonium tetrafluoroborate $(78 \mathrm{mg}, 0.27 \mathrm{mmol})$ were dissolved in dry toluene $(12 \mathrm{~mL})$ under argon atmosphere, and then stirred at $110^{\circ} \mathrm{C}$ for $12 \mathrm{~h}$. After cooling to room temperature, the reaction mixture was extracted with dichloromethane, washed with brine, and dried over anhydrous $\mathrm{Na}_{2} \mathrm{SO}_{4}$. After removal of the solvent, the residue was purified by column chromatography on silica gel using petroleum ether/dichloromethane (2:1 by vol.) as the eluent. Finally, the product was obtained as a white powder, $1.18 \mathrm{~g}$, yield: $67 \%$. Mp: $283-285^{\circ} \mathrm{C}$. ${ }^{1} \mathrm{H} \mathrm{NMR}$ $\left(400 \mathrm{MHz}, \mathrm{CDCl}_{3}\right) \delta$ (ppm): $7.91(\mathrm{~d}, J=8 \mathrm{~Hz}, 2 \mathrm{H}), 7.69$ $(\mathrm{d}, J=8 \mathrm{~Hz}, 2 \mathrm{H}), 7.54\left(\mathrm{dd}, J_{1}=16 \mathrm{~Hz}, J_{2}=8 \mathrm{~Hz}, 4 \mathrm{H}\right), 7.29$ $(\mathrm{d}, J=8 \mathrm{~Hz}, 2 \mathrm{H}), 7.05(\mathrm{~d}, J=8 \mathrm{~Hz}, 2 \mathrm{H}), 6.95-6.90(\mathrm{~m}$, $6 \mathrm{H}), 6.82(\mathrm{~d}, J=8 \mathrm{~Hz}, 2 \mathrm{H}), 6.71\left(\mathrm{dd}, J_{1}=16 \mathrm{~Hz}, J_{2}=8 \mathrm{~Hz}\right.$, $4 \mathrm{H}), 6.38(\mathrm{~d}, J=8 \mathrm{~Hz}, 2 \mathrm{H}), 5.20(\mathrm{~s}, 2 \mathrm{H}), 3.83(\mathrm{~s}, 3 \mathrm{H}), 2.11$ $(\mathrm{s}, 6 \mathrm{H}), 1.42(\mathrm{~s}, 9 \mathrm{H}) .{ }^{13} \mathrm{C} \mathrm{NMR}\left(100 \mathrm{MHz}, \mathrm{CDCl}_{3}\right) \delta$ (ppm): 158.6, 150.8, 141.1, 140.1, 138.7, 137.3, 136.2, $133.1,132.9,132.5,131.7,131.6,129.6,129.4,129.3,128.0$, $127.2,126.9,126.5,125.9,120.8,114.4,113.9,112.5,100.0$, 55.4, 50.7, 47.1, 34.7, 31.4, 20.7. HRMS (ESI): $\mathrm{m} / z[\mathrm{M}+$ $\mathrm{H}]^{+}$calcd. for $\mathrm{C}_{51} \mathrm{H}_{47} \mathrm{~N}_{2} \mathrm{O}^{+}$: 703.3683; found: 703.3680 .

Synthesis of 10'-(4'-(tert-butyl)-[1,1'-biphenyl]-4-yl)2,7-dimethyl-10H,10'H-9,9'-spirobi[acridine] (PMSBA). Compound B (1.05 g, $1.5 \mathrm{mmol})$, Pd on carbon (10\%) and formic acid $(0.5 \mathrm{~mL})$ in a mixed solvent of $\mathrm{CH}_{2} \mathrm{Cl}_{2}$ $(6 \mathrm{~mL})$ and $\mathrm{CH}_{3} \mathrm{OH}(3 \mathrm{~mL})$ were degassed with hydrogen for five times. After stirring at room temperature for $12 \mathrm{~h}$, the reaction mixture was treated with $\mathrm{CH}_{2} \mathrm{Cl}_{2}$, and then filtrated through kieselguhr. The combined organic phase was dried over $\mathrm{Na}_{2} \mathrm{SO}_{4}$. After removal of the solvent, the residue was purified by column chromatography on silica gel using petroleum ether/dichloromethane (1:1 by vol.) as the eluent to afford a white powder, $716 \mathrm{mg}$, yield: 82\%. Mp: $264-268^{\circ} \mathrm{C} .{ }^{1} \mathrm{H}$ NMR $\left(400 \mathrm{MHz}, \mathrm{CDCl}_{3}\right) \delta$ (ppm): 7.92 (d, $J=8 \mathrm{~Hz}, 2 \mathrm{H}), 7.69$ (d, $J=8 \mathrm{~Hz}, 2 \mathrm{H}), 7.57-$ $7.51(\mathrm{~m}, 4 \mathrm{H}), 7.04(\mathrm{~d}, J=8 \mathrm{~Hz}, 2 \mathrm{H}), 6.93-6.85(\mathrm{~m}, 6 \mathrm{H})$, 6.73-6.65 (m, 4H), 6.38 (d, $J=8 \mathrm{~Hz}, 2 \mathrm{H}), 6.12$ (br, $1 \mathrm{H})$. ${ }^{13} \mathrm{C} \mathrm{NMR}\left(100 \mathrm{MHz} \mathrm{CDCl}_{3}\right) \delta$ (ppm): 150.9, 141.1, 140.1, $138.7,137.3,132.5,131.6,129.6,127.9,126.9,126.4,126.0$, $120.7,113.9,113.1,34.7,31.4,21.0$. HRMS (ESI): $m / z$ [M
$+\mathrm{H}]^{+}$calcd. for $\mathrm{C}_{43} \mathrm{H}_{39} \mathrm{~N}_{2}^{+}$: 583.3108; found: 583.3106 .

Synthesis of 2-(4'-(tert-butyl)-[1,1'-biphenyl]-4-yl)-6(2,7-dimethyl-10H-spiro[acridine-9,9'-fluoren]-10-yl)$1 H$-benzo[de]isoquinoline-1,3(2H)-dione

(PhNAIMFAC). BrPhNAI (1.06 g, $2.2 \mathrm{mmol}), 2$,7-dimethyl-10Hspiro[acridine-9,9'-fluorene] (MFAC) (718 mg, $2.0 \mathrm{mmol})$, sodium tert-butoxide $(211 \mathrm{mg}, 2.2 \mathrm{mmol})$, palladium(II) acetate $(14 \mathrm{mg}, 0.06 \mathrm{mmol})$ and tri-tertbutylphosphonium tetrafluoroborate $(52 \mathrm{mg}, 0.18 \mathrm{mmol})$ were dissolved in dry toluene $(10 \mathrm{~mL})$ under argon atmosphere and then stirred at $110^{\circ} \mathrm{C}$ for $24 \mathrm{~h}$. After cooling to room temperature, the reaction mixture was extracted with dichloromethane, washed with brine, and dried over anhydrous $\mathrm{Na}_{2} \mathrm{SO}_{4}$. After removal of the solvent, the residue was purified by column chromatography on silica gel using petroleum ether/dichloromethane (1:2 by vol.) as the eluent. Finally, the product was obtained as a red powder, $1.22 \mathrm{~g}$, yield: $80 \%$. Mp: $396-397^{\circ} \mathrm{C} .{ }^{1} \mathrm{H}$ NMR (400 MHz, $\left.\mathrm{CD}_{2} \mathrm{Cl}_{2}\right) \delta(\mathrm{ppm}): 8.92(\mathrm{~d}, J=8 \mathrm{~Hz}, 1 \mathrm{H})$, $8.71(\mathrm{~d}, J=8 \mathrm{~Hz}, 1 \mathrm{H}), 8.22(\mathrm{~d}, J=8 \mathrm{~Hz}, 1 \mathrm{H}), 8.02(\mathrm{~d}, J=$ $8 \mathrm{~Hz}, 1 \mathrm{H}), 7.92(\mathrm{~d}, J=8 \mathrm{~Hz}, 1 \mathrm{H}), 7.87(\mathrm{~d}, J=8 \mathrm{~Hz}, 1 \mathrm{H})$, $7.83-7.79(\mathrm{~m}, 3 \mathrm{H}), 7.66(\mathrm{~d}, J=8 \mathrm{~Hz}, 2 \mathrm{H}), 7.55(\mathrm{~d}, J=$ $8 \mathrm{~Hz}, 2 \mathrm{H}), 7.52-7.48(\mathrm{~m}, 2 \mathrm{H}), 7.46-7.38(\mathrm{~m}, 5 \mathrm{H}), 7.28(\mathrm{t}, J$ $=8 \mathrm{~Hz}, 1 \mathrm{H}), 6.65(\mathrm{~d}, J=8 \mathrm{~Hz}, 2 \mathrm{H}), 6.23(\mathrm{~s}, 2 \mathrm{H}), 6.00(\mathrm{~d}, J$ $=8 \mathrm{~Hz}, 2 \mathrm{H}), 1.92(\mathrm{~s}, 6 \mathrm{H}), 1.39(\mathrm{~s}, 9 \mathrm{H}) .{ }^{13} \mathrm{C} \mathrm{NMR}$ $\left(100 \mathrm{MHz}, \mathrm{CD}_{2} \mathrm{Cl}_{2}\right) \delta$ (ppm): 164.1, 163.8, 157.8, 156.3, $150.9,144.6,141.5,140.4,138.8,138.4,137.3,134.6,133.0$, $132.1,131.0,130.8,130.4,130.3,129.1,128.5,128.4,128.3$, $128.3,128.2,127.9,127.8,127.7,126.9,126.1,125.9,125.2$, $124.2,124.1,123.3,120.2,120.2,114.6,56.7,34.5,31.1$, 20.0. HRMS (ESI): $m / z[\mathrm{M}+\mathrm{H}]^{+}$calcd. for $\mathrm{C}_{55} \mathrm{H}_{43} \mathrm{~N}_{2} \mathrm{O}_{2}{ }^{+}$: 763.3319; found: 763.3306.

Synthesis of PhNAI-PMSBA. A similar procedure to the preparation of PhNAI-MFAC was used but empolying PMSBA instead of MFAC. A red powder was obtained with the yield of $84 \%$. Mp: $445-446^{\circ} \mathrm{C} .{ }^{1} \mathrm{H}$ NMR (400 MHz, $\mathrm{CD}_{2} \mathrm{Cl}_{2}$ ) $\delta$ (ppm): 8.91 (d, $\left.J=8 \mathrm{~Hz}, 1 \mathrm{H}\right), 8.72$ $(\mathrm{d}, J=8 \mathrm{~Hz}, 1 \mathrm{H}), 8.28$ (d, $J=8 \mathrm{~Hz}, 1 \mathrm{H}), 7.98$ (t, $J=8 \mathrm{~Hz}$, $3 \mathrm{H}), 7.83-7.78(\mathrm{~m}, 3 \mathrm{H}), 7.71(\mathrm{~d}, J=8 \mathrm{~Hz}, 2 \mathrm{H}), 7.67(\mathrm{~d}, J$ $=8 \mathrm{~Hz}, 2 \mathrm{H}), 7.58-7.54(\mathrm{~m}, 6 \mathrm{H}), 7.45(\mathrm{~d}, J=8 \mathrm{~Hz}, 2 \mathrm{H})$, $7.23(\mathrm{t}, J=8 \mathrm{~Hz}, 2 \mathrm{H}), 7.06(\mathrm{~s}, 2 \mathrm{H}), 7.00-6.86(\mathrm{~m}, 3 \mathrm{H})$, $6.80(\mathrm{t}, J=8 \mathrm{~Hz}, 1 \mathrm{H}), 6.66(\mathrm{~d}, J=8 \mathrm{~Hz}, 2 \mathrm{H}), 6.47\left(\mathrm{q}, J_{1}=\right.$ $\left.16 \mathrm{~Hz}, J_{2}=8 \mathrm{~Hz}, 2 \mathrm{H}\right), 5.96(\mathrm{~d}, J=8 \mathrm{~Hz}, 2 \mathrm{H}), 2.10(\mathrm{~s}, 6 \mathrm{H})$, $1.41(\mathrm{~s}, 18 \mathrm{H}) .{ }^{13} \mathrm{C} \mathrm{NMR}\left(100 \mathrm{MHz}, \mathrm{CD}_{2} \mathrm{Cl}_{2}\right) \delta$ (ppm): 166.0, 165.7, 152.9, 152.8, 146.5, 143.5, 143.2, 141.8, 141.3, $140.0,139.3,139.1,138.1,136.6,134.9,134.8,134.2,134.1$, $133.6,133.5,133.4,133.0,132.9,132.7,132.5,132.2,131.5$, $131.1,130.2$, 129.8, 129.8, 128.8, 128.7, 128.7, 128.6, 127.9, $127.8,126.0,125.2,122.7,122.6,116.4,116.3,115.8,48.9$, 36.5, 36.4, 33.0, 22.2. HRMS (ESI): $m / z[\mathrm{M}+\mathrm{H}]^{+}$calcd. 
for $\mathrm{C}_{71} \mathrm{H}_{60} \mathrm{~N}_{3} \mathrm{O}_{2}^{+}$: 986.4680; found: 986.4689 .

\section{RESULTS AND DISCUSSION}

\section{DFT calculations}

Before synthesis, density functional theory (DFT) and time-dependent DFT calculations were performed on PhNAI-MFAC and PhNAI-PMSBA to predict their geometric structures and electronic characteristics. The optimized ground state structure of PhNAI-PMSBA was highly twisted, coupled with a dihedral angle of $85.0^{\circ}$ between the acceptor and donor units. This facilitates good separation between the highest occupied molecular orbit (HOMO) and the lowest unoccupied molecular orbit (LUMO) distributions (Figs S1, S2) and thus results in a small energy gap $\left(\Delta E_{\mathrm{ST}}\right)$ of $0.04 \mathrm{eV}$ between the lowest singlet state $\left(\mathrm{S}_{1}\right)$ and the lowest triplet state $\left(\mathrm{T}_{1}\right)$, potentially activating the RISC process (Fig. 2a and Table S1). The introduction of methyl groups in the AC unit of PhNAI-PMSBA afforded some HOMO-LUMO overlap, leading to a oscillator strength $(f)$ of 0.0043 . This reveals the decent emissive ability of PhNAI-PMSBA. The simulation of electrostatic surface on both molecules revealed that PhNAI-PMSBA had a significantly longer molecular length (38.2 $\AA$ ) along the $x$ axis than PhNAIMFAC (28.8 $\AA$ ). Meanwhile, the aspect ratio of molecular length to width for PhNAI-PMSBA (2.77) was much larger compared with 1.99 for PhNAI-MFAC (Fig. 2b and Table S2) [32]. The elongated molecular long axis of PhNAI-PMSBA may lead to a better horizontal molecular orientation.

\section{Synthesis and characterization}

As depicted in Scheme 1, A was firstly prepared by lithium-halogen reaction, nucleophilic substitution reaction, Friedel-Crafts reaction and acid-catalyzed cleavage of the 2-methoxyethoxymethyl group. Afterward, the linear donor unit, PMSBA, was synthesized by Pd-catalyzed C-N coupling reaction, followed by Pd-catalyzed hydrogenation reaction. Finally, the target molecule of PhNAI-PMSBA was obtained by Pd-catalyzed C-N coupling reaction of the PMSBA donor with the tert-butylbiphenyl-substituted NAI acceptor. By integrating a control donor moiety, MFAC, the reference molecule, PhNAI-MFAC, was also synthesized for comparison. Xray crystallographic analysis was performed on single crystals of the compounds PhNAI-MFAC and PhNAIPMSBA (Fig. 3 and Table S3). Both molecules exhibited highly twisted conformation, accompanied with nearly orthogonal dihedral angles between the donor and acceptor moieties $\left(82.3^{\circ}\right.$ for PhNAI-MFAC and $86.7^{\circ}$ for PhNAI-PMSBA). PhNAI-PMSBA preferred a linear molecular shape in $35.7 \AA$ length, much longer than the length of $24.9 \AA$ for PhNAI-MFAC. These results are in good agreement with the DFT simulation. In the molecular packing diagram, PhNAI-PMSBA exhibited an orderly anti-parallel arrangement. No $\pi-\pi$ stacking was observed in the crystal of PhNAI-PMSBA except some short contacts such as $\mathrm{C}-\mathrm{H}-\pi$ and $\mathrm{C}=\mathrm{O}-\mathrm{H}$. This suggests that the intermolecular interaction of PhNAI-PMSBA is relatively weak. Besides, PhNAI-PMSBA was thermally stable to $>450^{\circ} \mathrm{C}$ (Fig. S3), rendering it well suited for a vacuum deposition process. In cyclic voltammetry mea-
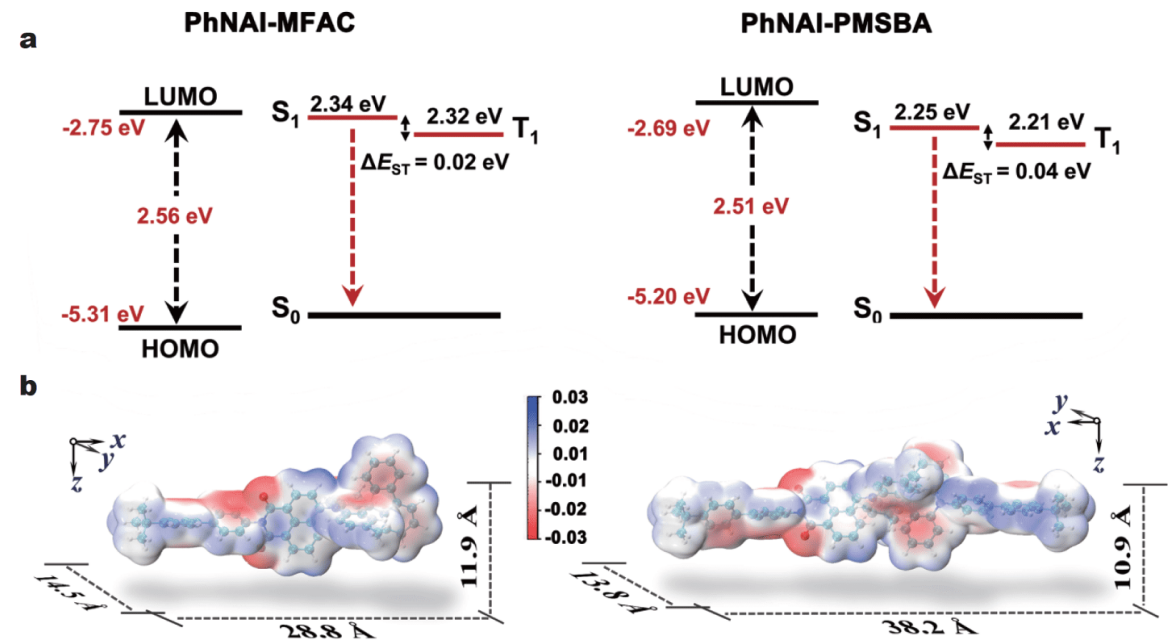

Figure 2 (a) Calculated energy levels and (b) calculated electrostatic surface potentials at $\rho=0.001 \mathrm{e} \mathrm{bohr}^{-3}$ with optimized ground state structures. 

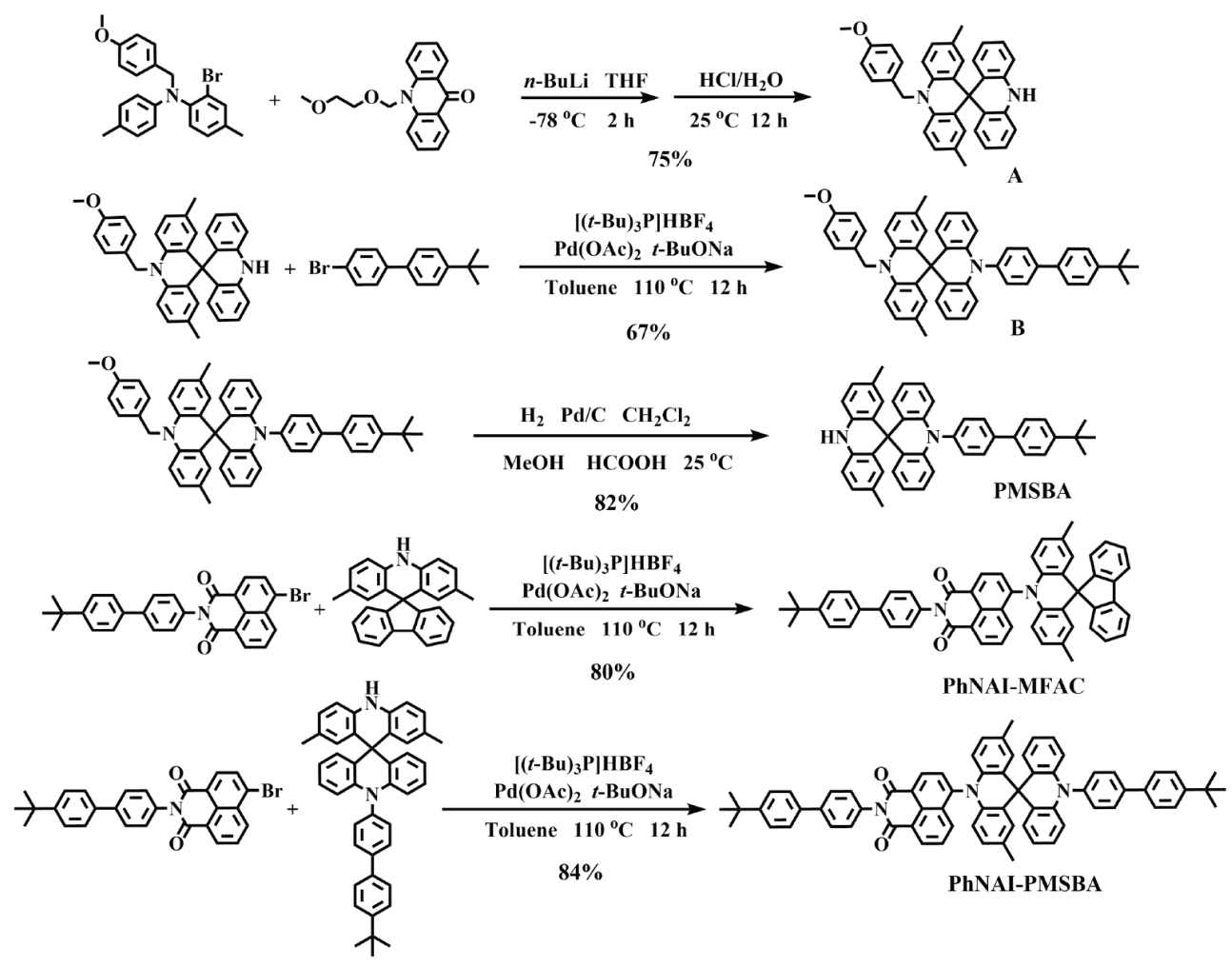

Scheme 1 Syntheses of PhNAI-MFAC and PhNAI-PMSBA.

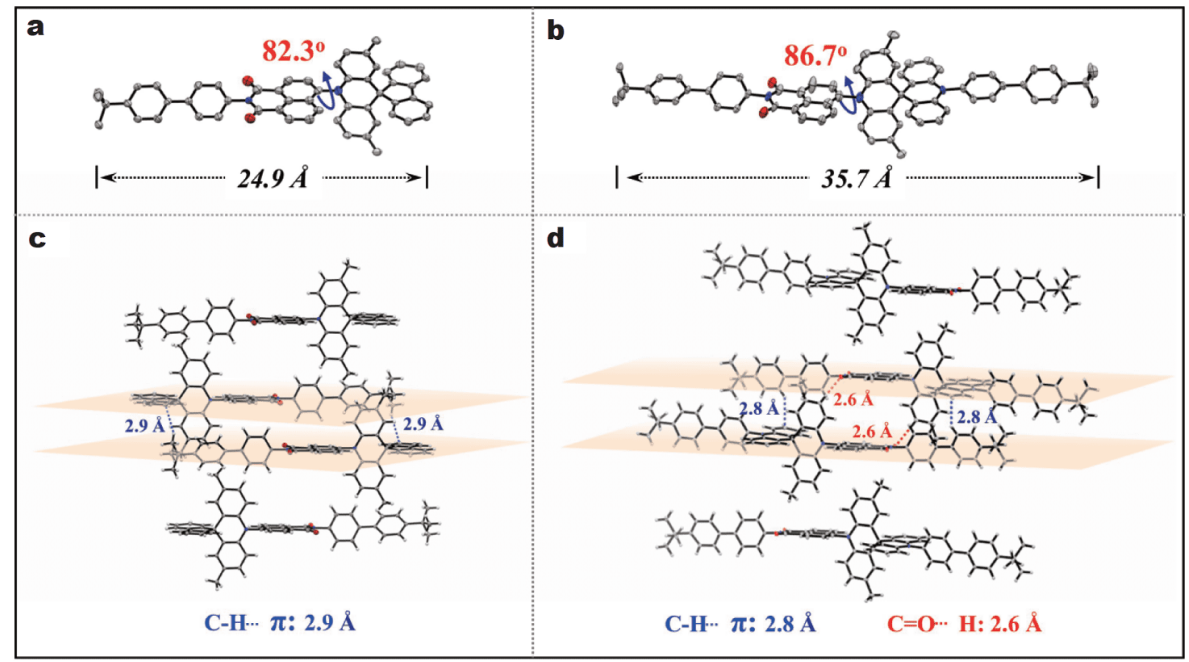

Figure 3 Oak ridge thermal ellipsoid plot (ORTEP) diagrams of (a) PhNAI-MFAC and (b) PhNAI-PMSBA without showing hydrogen atoms. Molecular packing diagram of (c) PhNAI-MFAC and (d) PhNAI-PMSBA in a single crystal.

surements, PhNAI-PMSBA exhibited the double-electron oxidation process, which could be assigned to the different acridine units in the PMSBA donor (Fig. S4). Moreover, both emitters displayed one-electron reduction behavior arising from the acceptor unit. The HOMO/

LUMO levels were obtained as $-5.31 /-3.21 \mathrm{eV}$ and $-5.34 /-3.30 \mathrm{eV}$ for PhNAI-MFAC and PhNAI-PMSBA, respectively. 


\section{Photophysical properties}

Ultraviolet-visible (UV-vis) absorption spectra of PhNAIMFAC and PhNAI-PMSBA in toluene showed local excited (LE) transition peaks below $380 \mathrm{~nm}$ and ICT absorption bands around $500 \mathrm{~nm}$ (Fig. 4a). Similar to PhNAI-MFAC, PhNAI-PMSBA in toluene solution showed a structureless and red emission peaking at $628 \mathrm{~nm}$. In addition, the optical properties of both emitters in the 9-(3-(9H-carbazol-9-yl)phenyl)-9H-carbazole-3-carbonitrile (mCPCN) host were also studied (Fig. 4b). Both emitters in the $\mathrm{mCPCN}$ host displayed similar ICT-featured emission profiles with main peaks at 603 and $606 \mathrm{~nm}$ for PhNAI-MFAC and PhNAI-PMSBA, respectively. Furthermore, PhNAI-PMSBA had similar $\mathrm{S}_{1} / \mathrm{T}_{1}$ levels with respect to PhNAI-MFAC (Table 1). This result strongly suggests the double-site long-axis extension approach rarely affects the excited states of emitters. Accordingly, both emitters in the mCPCN host possessed small $\Delta E_{\mathrm{ST}}$ values of $<0.1 \mathrm{eV}$. As expected, the transient photoluminescence $(\mathrm{PL})$ spectra of both emitters showed second-order exponential decays both in toluene solution and the mCPCN host (Fig. 4c and Figs S5, S6). The intensities of delayed fluorescence component increased as the temperature rose from 200 to $300 \mathrm{~K}$, demonstrating their distinct TADF nature (Fig. S7). The delayed fluorescence lifetime $\left(\tau_{\mathrm{d}}\right)$ of PhNAI-PMSBA was fitted as short as $2.7 \mu$ s (Table 1 and Table S4), indicative of its effective RISC process [35,36]. Moreover, PhNAI-PMSBA exhibited PL quantum yield $\left(\Phi_{\mathrm{PL}}\right)$ and radiative rate constant $\left(k_{\mathrm{r}, \mathrm{S}}\right)$ comparable to PhNAI-MFAC in the mCPCN host $\left(\Phi_{\mathrm{PL}}=55 \%\right.$ and $61 \%$, and $k_{\mathrm{r}, \mathrm{S}}=0.90 \times 10^{7}$ and $1.74 \times$ $10^{7} \mathrm{~s}^{-1}$, respectively).

\section{Dipole orientation}

To explore the influence of molecular length on the molecular orientation and dipole alignment, the $S_{1} \rightarrow S_{0}$ transition dipole moments (TDMs) of both molecules were firstly simulated using the nuclear ensemble approach [37]. The TDM vectors of both molecules mainly aligned to the molecular long axis ( $x$ axis) (Fig. 5a, b), accompanied with large $x$ components and small $y$ and $z$ components. In comparison with PhNAI-MFAC, the TDM vectors of PhNAI-PMSBA had larger $x$ component and smaller $y$ and $z$ components. This result strongly indicates that PhNAI-PMSBA exhibited better agreement between the TDM direction and the molecular long axis.
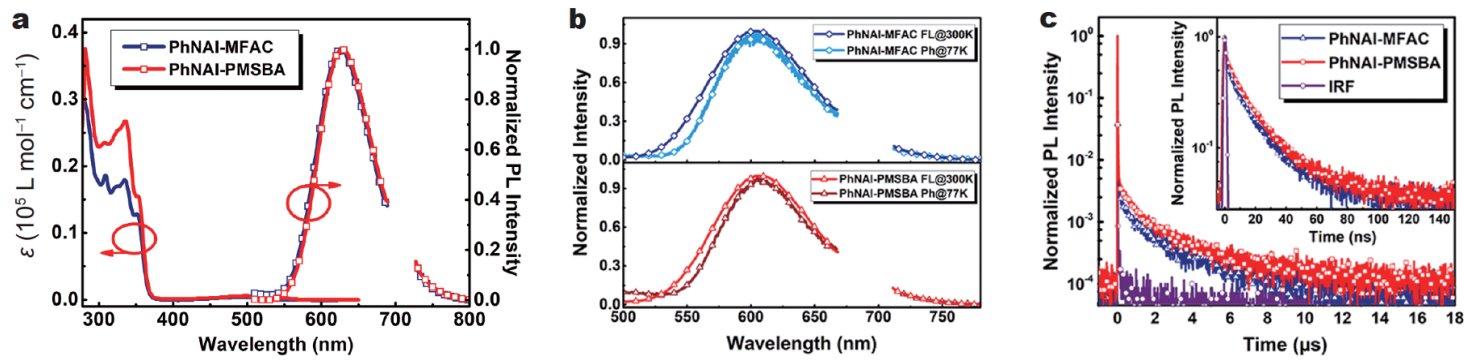

Figure 4 (a) UV-vis absorption spectra and normalized PL spectra of PhNAI-MFAC and PhNAI-PMSBA in toluene solutions $\left(1 \times 10^{-5}\right.$ mol $\left.\mathrm{L}^{-1}\right)$ at $300 \mathrm{~K}\left(2^{\text {nd }}\right.$ harmonic wavelength of excitation has been deleted as break in PL spectra). (b) Normalized fluorescence (300 K) and phosphorescence (77 K) spectra of $1.5 \mathrm{wt} \%$ PhNAI-MFAC and PhNAI-PMSBA doped into the mCPCN host $\left(2^{\text {nd }}\right.$ harmonic wavelength of excitation has been deleted as break in PL spectra). (c) Transient PL spectra of $1.5 \mathrm{wt} \%$ PhNAI-MFAC and PhNAI-PMSBA doped into the mCPCN host (inset: prompt components for these transient PL spectra).

Table 1 Summary of the optical properties of PhNAI-MFAC and PhNAI-PMSBA

\begin{tabular}{cccccccccccc}
\hline Compound & $\begin{array}{c}\lambda_{\mathrm{abs}} \\
(\mathrm{nm})^{\mathrm{a}}\end{array}$ & $\lambda_{\mathrm{em}}(\mathrm{nm})^{\mathrm{a}}$ & $\lambda_{\mathrm{em}}(\mathrm{nm})^{\mathrm{b}}$ & $\begin{array}{c}S_{1} / T_{1} \\
(\mathrm{eV})^{\mathrm{c}}\end{array}$ & $\Delta E_{\mathrm{ST}}(\mathrm{eV})^{\mathrm{d}}$ & $\tau_{\mathrm{p}}(\mathrm{ns})^{\mathrm{e}}$ & $\tau_{\mathrm{d}}(\mu \mathrm{s})^{\mathrm{e}}$ & $\Phi_{\mathrm{PL}}(\%)^{\mathrm{f}}$ & $\Phi_{\mathrm{PF}}(\%)^{\mathrm{f}}$ & $\Phi_{\mathrm{DF}}(\%)^{\mathrm{f}}$ & $\Theta_{/ /}(\%)^{\mathrm{g}}$ \\
\hline PhNAI-MFAC & $\begin{array}{c}280 / 308 / \\
335 / 499\end{array}$ & 625 & 603 & $2.33 / 2.27$ & 0.06 & 15.0 & 2.9 & 61 & 26 & 35 \\
PhNAI-PMSBA & $\begin{array}{c}282 / 335 / \\
499\end{array}$ & 628 & 606 & $2.32 / 2.27$ & 0.05 & 15.9 & 2.7 & 55 & 14 & 41 & 95 \\
\hline
\end{tabular}

a) Measured in toluene $\left(1 \times 10^{-5} \mathrm{~mol} \mathrm{~L}^{-1}\right)$ at room temperature; b) measured in the mCPCN host; c) obtained from the onsets of fluorescence spectra and phosphorescence spectra of both emitters in the mCPCN host; d) calculated from $S_{1}$ and $T_{1}$; e) lifetimes for the prompt and delayed fluorescence components of both emitters in the mCPCN host; f) PL quantum yield, quantum yield for the prompt $\left(\Phi_{\mathrm{PF}}\right)$ and delayed $\left(\Phi_{\mathrm{DF}}\right)$ fluorescence of both emitters in the mCPCN host at room temperature; g) horizontal dipole ratios of both emitters in the mCPCN host. Note: doping concentrations were $1.5 \mathrm{wt} \%$ for PhNAI-MFAC and PhNAI-PMSBA. 
a

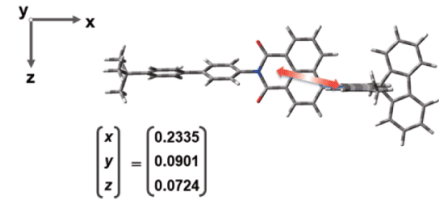

b

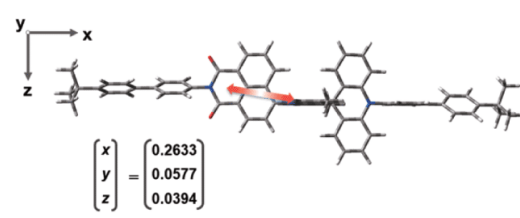

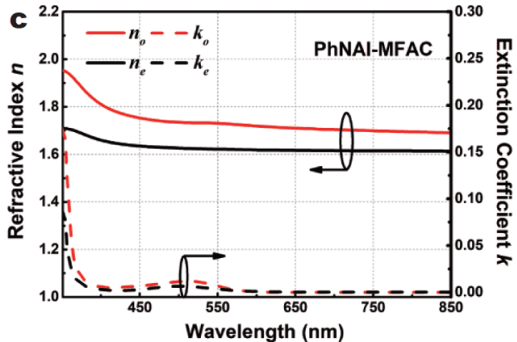

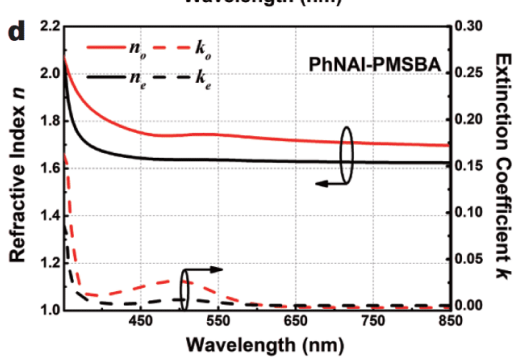

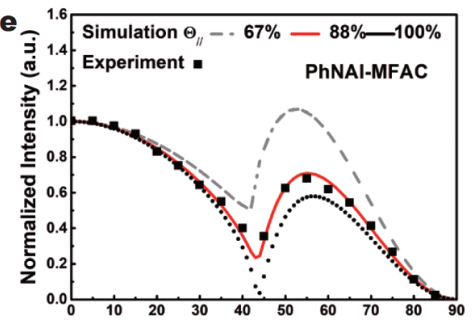

Angle (degree)

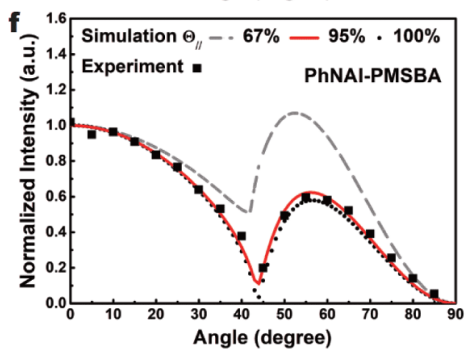

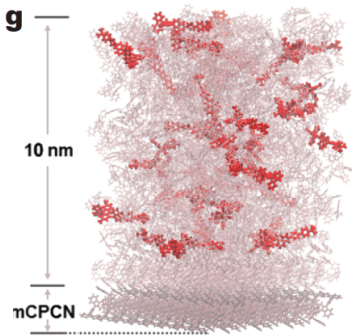
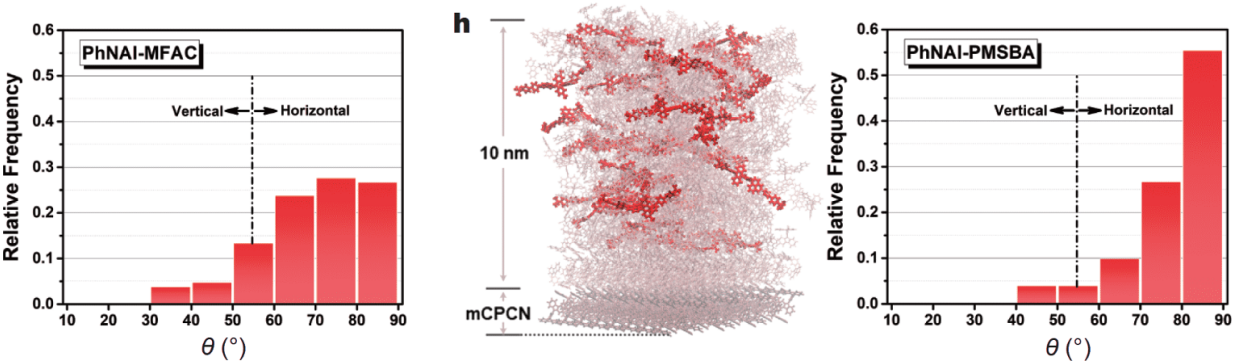

Figure 5 Simulated transition dipole moment (as indicated by arrow) of (a) PhNAI-MFAC and (b) PhNAI-PMSBA with optimized $\mathrm{S}_{1}$ structure. Ordinary (red lines) and extraordinary (dark lines) refractive indices $\left(n_{\mathrm{o}}, n_{\mathrm{e}}\right)$ and extinction coefficients $\left(k_{\mathrm{o}}, k_{\mathrm{e}}\right)$ of $(\mathrm{c})$ PhNAI-MFAC and (d) PhNAIPMSBA in neat films. Angular dependent $p$-polarized PL intensity of (e) PhNAI-MFAC and (f) PhNAI-PMSBA in the mCPCN host. Molecular stacking diagram and angular probability distributions of (g) PhNAI-MFAC and (h) PhNAI-PMSBA simulated by MD calculations (red molecules represent emitters and others represent $\mathrm{mCPCN}$ host).

Simultaneously, variable angle spectroscopic ellipsometry study also revealed that both emitters exhibited larger ordinary (horizontal) refractive indices $\left(n_{0}\right)$ and extinction coefficients $\left(k_{o}\right)$ than extraordinary (vertical) parameters $\left(n_{e}, k_{e}\right)$ (Fig. $5 c, d$ ), indicating that both emitters showed intrinsically anisotropic properties in neat film [4]. Furthermore, PhNAI-PMSBA delivered larger differences between ordinary and extraordinary parameters compared with PhNAI-MFAC. Such results clearly indicate that PhNAI-PMSBA had a stronger tendency to exhibit horizontal alignment. To further determine this point, we measured angular dependent $p$-polarized PL intensity of both emitters in the mCPCN host (Fig. 5e, f). The $\Theta_{/ /}$of PhNAI-PMSBA was extracted as high as $95 \%$. This value is among the best results reported so far for horizontally oriented emitters. The higher $\Theta_{/ /}$of PhNAIPMSBA over PhNAI-MFAC $\left(\Theta_{\|}=88 \%\right)$ testified the validity of the double-site long-axis extension strategy in realizing horizontal dipole orientation. To get deeper insights, MD simulations were carried out to mimic the vacuum deposition process of both emitters doped into the mCPCN host [38]. PhNAI-MFAC and PhNAIPMSBA were prone to form no aggregates when doping into the mCPCN host molecules (Fig. 5g, h). Although the angles $(\theta)$ between molecular long axis and the normal direction of the substrate surface varied from $30^{\circ}$ to $90^{\circ}$ for PhNAI-MFAC and PhNAI-PMSBA, $\theta$ with the values higher than $55^{\circ}\left(\theta \approx 55^{\circ}\right.$ corresponding to random orientation) contributed much more possibility. This suggests that both emitter molecules are likely to align along their molecular long axis on a substrate surface. Accordingly, the ensemble average $\theta$ of both emitters were simulated as $70.0^{\circ} \pm 2.6^{\circ}$ and $77.9^{\circ} \pm 2.1^{\circ}$ for PhNAI-MFAC and PhNAI-PMSBA, respectively. The larger ensemble average $\theta$ of PhNAI-PMSBA reveals its better horizontal molecular orientation. During the mimicked vacuum deposition, the average drift angles relative to the ultimate states for both emitters were 
gradually reduced as the emitters covered by the following molecules, indicating the gradually stabilized molecular orientation (Fig. S8a). The fast reduction of average drift angle at the initial stage suggests both emitters quickly approached the final molecular orientation at the film surface. Consequently, the designed emitters exhibited rapidly decreased fluctuation at the initial stage and then equilibrated in the bulk (Fig. S8b). In comparison with PhNAI-MFAC, PhNAI-PMSBA revealed the smaller fluctuation range of $\theta$ during the deposition process. This suggests that PhNAI-PMSBA showed a better intrinsical tendency to keep its molecular orientation horizontal. To sum up, the double-site long-axis extension strategy can actively enhance horizontal molecular orientation and thus induce the preferred dipole alignment of emitters, which may benefit the light extraction of OLEDs.

\section{Electroluminescent properties}

To evaluate the effect of orientation of emitters on device performance, multi-layer OLEDs with a typical configuration of indium tin oxide (ITO)/ $/ \mathrm{MoO}_{3}(2 \mathrm{~nm}) / \mathrm{di}$-[4( $\mathrm{N}, \mathrm{N}$-ditolyl-amino)-phenyl]-cyclohexane

(TAPC) $(60 \mathrm{~nm}) / \mathrm{N}, \mathrm{N}$-dicarbazolyl-3,5-benzene $(\mathrm{mCP})(10 \mathrm{~nm})$ /emissive layer (EML) $(20 \mathrm{~nm}$ )/tris-[3-(3-pyridyl)mesityl] borane (3TPYMB) $(80 \mathrm{~nm}) / \mathrm{LiF}(1 \mathrm{~nm}) / \mathrm{Al}$ (Fig. 6a, b) were fabricated. PhNAI-MFAC or PhNAI-PMSBA (1.5 wt\%) was doped into the mCPCN host as the EML. Similar to the PL in the mCPCN host, both devices ex- hibited broad and red electroluminescence (EL) with main peaks at 610 and $615 \mathrm{~nm}$ for PhNAI-MFAC and PhNAI-PMSBA, respectively (Fig. 6c), corresponding to favorable CIE 1931 coordinates of $(0.59,0.41)$ and $(0.60$, 0.40). Moreover, both devices displayed similar current density-voltage-luminance $(J-V-L)$ characteristics with the same turn-on voltages of $3.1 \mathrm{~V}$ (Fig. 6d). The PhNAIPMSBA-based device achieved outstanding EL performance with maximum current efficiency $\left(\eta_{c}\right)$ of $34.3 \mathrm{~cd} \mathrm{~A} \mathrm{~A}^{-1}$, a maximum power efficiency $\left(\eta_{\mathrm{p}}\right)$ of $35.9 \mathrm{~lm} \mathrm{~W}{ }^{-1}$ and a maximum $\eta_{\text {ext }}$ of $22.3 \%$ (Fig. 6e and Table 2). These values are among the best EL performance for red TADF OLEDs [39-41]. It is also noted the resulting OLEDs suffer from severe efficiency roll-off at high luminance, which can be alleviated by optimizing doping concentration of both emitters in the host matrix (Fig. S9 and Table S5). Although the $\Phi_{\mathrm{PL}}$ followed the trend in PhNAI-PMSBA < PhNAI-MFAC, the PhNAIPMSBA-based device still delivered an external quantum efficiency comparable to the control device based on PhNAI-MFAC $\left(\eta_{\text {ext }}=22.5 \%\right)$. This may be associated with different $\Theta_{/ /}$values of both emitters. According to the classical oscillating dipole model and the obtained $\Theta_{/ /}$ values, the $\Phi_{\text {out }}$ of the PhNAI-PMSBA-based device was simulated to be $43.2 \%$, superior to the $\Phi_{\text {out }}(40.3 \%)$ of the PhNAI-MFAC-based control device. Furthermore, the $43.2 \% \Phi_{\text {out }}$ is close to the theoretical limit of $45.2 \%$ for fully horizontal oriented emitters and is significantly higher than $30.6 \%$ for isotropic emitters simulated in the
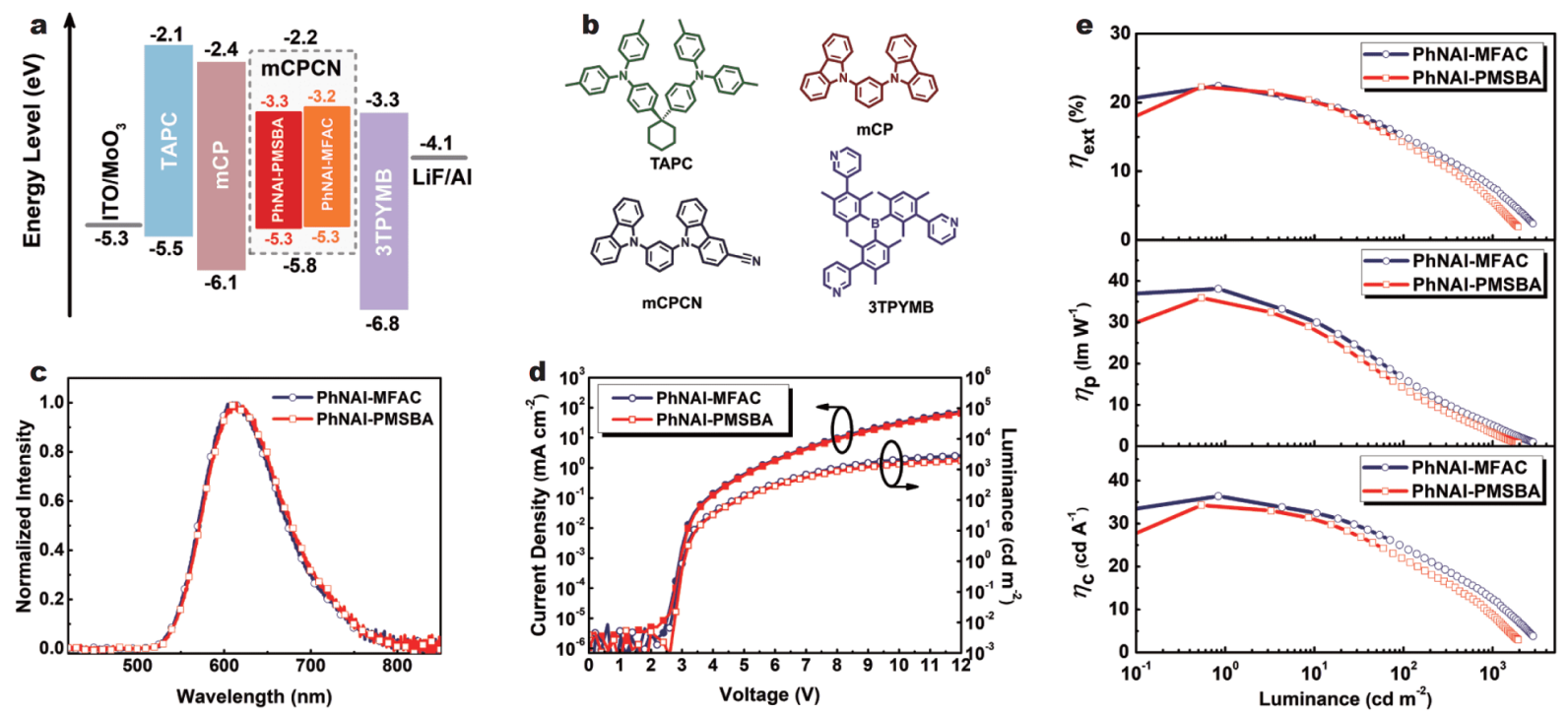

Figure 6 (a) Energy level diagram and (b) molecular structures of materials used in the devices. (c) EL spectra and (d) current density-voltageluminance characteristics for the devices. (e) External quantum efficiency, power efficiency and current efficiency versus luminance curves for the devices. 
Table 2 The key EL data of the resulting OLEDs

\begin{tabular}{ccccccccc}
\hline Emitter & $V_{\text {on }}(\mathrm{V})^{\mathrm{a}}$ & $\mathrm{EL}_{\text {peak }}(\mathrm{nm})^{\mathrm{b}}$ & $\eta_{\mathrm{c}}\left(\mathrm{cd} \mathrm{A}^{-1}\right)^{\mathrm{c}}$ & $\eta_{\mathrm{p}}\left(\mathrm{lm} \mathrm{W}^{-1}\right)^{\mathrm{d}}$ & $\eta_{\text {ext }}(\%)^{\mathrm{e}}$ & $\Phi_{\text {out }}(\%)^{\mathrm{f}}$ & $\Phi_{\text {out }} \times \Phi_{\text {PL }}(\%)^{\mathrm{g}}$ & $\mathrm{CIE}_{(\mathrm{x}, \mathrm{y})^{\mathrm{h}}}$ \\
\hline PhNAI-MFAC & 3.1 & 610 & $36.4,24.5,12.4$ & $38.1,16.4,5.0$ & $22.5,15.1,7.6$ & 40.3 & 24.7 & $0.59,0.41$ \\
PhNAI-PMSBA & 3.1 & 615 & $34.3,22.0,8.7$ & $35.9,14.4,3.3$ & $22.3,14.3,5.7$ & 43.2 & 23.8 & $0.60,0.40$ \\
\hline
\end{tabular}

a) The turn-on voltage recorded at a brightness of $1 \mathrm{~cd} \mathrm{~m}^{-2}$; b) emission peak of EL spectra; maximum value, values at 100 and $1000 \mathrm{~cd} \mathrm{~m}{ }^{-2}$ of $\mathrm{c}$ ) current efficiency, d) power efficiency and e) external quantum efficiency; f) optical out-coupling efficiency; g) the upper limit of external quantum efficiency; h) CIE 1931 coordinates.

same device architecture (Fig. S10). In this sense, the ultrahigh $\Phi_{\text {out }}$ of $43.2 \%$ and the inspiring $\eta_{\text {ext }}$ of over $22 \%$ for the PhNAI-PMSBA-based device demonstrate the importance of controlling dipole orientation in upgrading device performance.

\section{CONCLUSIONS}

In summary, a red TADF emitter, PhNAI-PMSBA, with a linear molecular shape was developed by a double-site long-axis extension strategy. In comparison with the single-site extended reference molecule, the molecular shape of PhNAI-PMSBA was effectively elongated, resulting in a better horizontal molecular orientation and a higher horizontal dipole ratio of $95 \%$. To the best of our knowledge, the horizontal dipole ratio of $95 \%$ is among the best values for horizontally oriented emitters. Molecular dynamics simulations and optical studies demonstrated the high horizontal dipole orientation of PhNAIPMSBA was attributed to the synergistic regulation in its molecular shape and transition dipole moment direction. Optical simulation delivered an ultrahigh outcoupling efficiency of $43.2 \%$ for the PhNAI-PMSBA-based device, far exceeding $30.6 \%$ for isotropic emitters. As a result, using PhNAI-PMSBA resulted in an external quantum efficiency of over $22 \%$ and a red EL emission with CIE 1931 coordinates at $(0.60,0.40)$. This work presents an effective approach to control organic emitter's dipole orientation, and further efforts in developing multicolor organic emitters with fully horizontal orientation is ongoing.

Received 9 June 2020; accepted 24 August 2020;

published online 12 November 2020

1 Jurow MJ, Mayr C, Schmidt TD, et al. Understanding and predicting the orientation of heteroleptic phosphors in organic lightemitting materials. Nat Mater, 2016, 15: 85-91

2 Zeng W, Lai HY, Lee WK, et al. Achieving nearly 30\% external quantum efficiency for orange-red organic light emitting diodes by employing thermally activated delayed fluorescence emitters composed of 1,8-naphthalimide-acridine hybrids. Adv Mater, 2018, 30: 1704961

3 Schmidt TD, Lampe T, Sylvinson M. R. D, et al. Emitter orientation as a key parameter in organic light-emitting diodes. Phys Rev
Appl, 2017, 8: 037001

4 Yokoyama D. Molecular orientation in small-molecule organic light-emitting diodes. J Mater Chem, 2011, 21: 19187-19202

5 Kim JS, Ho PKH, Greenham NC, et al. Electroluminescence emission pattern of organic light-emitting diodes: Implications for device efficiency calculations. J Appl Phys, 2000, 88: 1073-1081

$6 \mathrm{Kim} \mathrm{KH,} \mathrm{Kim} \mathrm{JJ.} \mathrm{Origin} \mathrm{and} \mathrm{control} \mathrm{of} \mathrm{orientation} \mathrm{of} \mathrm{phosphor-}$ escent and TADF dyes for high-efficiency OLEDs. Adv Mater, 2018, 30: 1705600

7 Smith LH, Wasey JAE, Samuel IDW, et al. Light out-coupling efficiencies of organic light-emitting diode structures and the effect of photoluminescence quantum yield. Adv Funct Mater, 2005, 15: 1839-1844

8 Zeng X, Pan KC, Lee WK, et al. High-efficiency pure blue thermally activated delayed fluorescence emitters with a preferentially horizontal emitting dipole orientation via a spiro-linked double DA molecular architecture. J Mater Chem C, 2019, 7: 10851-10859

9 Tumbleston JR, Collins BA, Yang L, et al. The influence of molecular orientation on organic bulk heterojunction solar cells. Nat Photon, 2014, 8: 385-391

10 Watanabe Y, Yokoyama D, Koganezawa T, et al. Control of molecular orientation in organic semiconductor films using weak hydrogen bonds. Adv Mater, 2019, 31: 1808300

11 Bekenstein Y, Koscher BA, Eaton SW, et al. Highly luminescent colloidal nanoplates of perovskite cesium lead halide and their oriented assemblies. J Am Chem Soc, 2015, 137: 16008-16011

12 Graf A, Liehm P, Murawski C, et al. Correlating the transition dipole moment orientation of phosphorescent emitter molecules in OLEDs with basic material properties. J Mater Chem C, 2014, 2: 10298-10304

13 Nakamura T, Shioya N, Shimoaka T, et al. Molecular orientation change in naphthalene diimide thin films induced by removal of thermally cleavable substituents. Chem Mater, 2019, 31: 1729-1737

14 Morgenstern T, Schmid M, Hofmann A, et al. Correlating optical and electrical dipole moments to pinpoint phosphorescent dye alignment in organic light-emitting diodes. ACS Appl Mater Interfaces, 2018, 10: 31541-31551

15 Uoyama H, Goushi K, Shizu K, et al. Highly efficient organic lightemitting diodes from delayed fluorescence. Nature, 2012, 492: 234238

16 Lv X, Wang H, Meng L, et al. Highly efficient inverted organic light-emitting diodes based on thermally activated delayed fluorescence. Sci China Mater, 2016, 59: 421-426

17 Etherington MK, Gibson J, Higginbotham HF, et al. Revealing the spin-vibronic coupling mechanism of thermally activated delayed fluorescence. Nat Commun, 2016, 7: 13680

18 Wu K, Zhang T, Wang Z, et al. De novo design of excited-state intramolecular proton transfer emitters via a thermally activated delayed fluorescence channel. J Am Chem Soc, 2018, 140: 88778886 
19 Wong MY, Zysman-Colman E. Purely organic thermally activated delayed fluorescence materials for organic light-emitting diodes. Adv Mater, 2017, 29: 1605444

20 Gong X, Li P, Huang YH, et al. A red thermally activated delayed fluorescence emitter simultaneously having high photoluminescence quantum efficiency and preferentially horizontal emitting dipole orientation. Adv Funct Mater, 2020, 30: 1908839

21 Lin TA, Chatterjee T, Tsai WL, et al. Sky-blue organic light emitting diode with $37 \%$ external quantum efficiency using thermally activated delayed fluorescence from spiroacridine-triazine hybrid. Adv Mater, 2016, 28: 6976-6983

22 Mayr C, Lee SY, Schmidt TD, et al. Efficiency enhancement of organic light-emitting diodes incorporating a highly oriented thermally activated delayed fluorescence emitter. Adv Funct Mater, 2014, 24: 5232-5239

23 Zhang D, Song X, Cai M, et al. Versatile indolocarbazole-isomer derivatives as highly emissive emitters and ideal hosts for thermally activated delayed fluorescent OLEDs with alleviated efficiency rolloff. Adv Mater, 2018, 30: 1705406

24 Yang Z, Mao Z, Xie Z, et al. Recent advances in organic thermally activated delayed fluorescence materials. Chem Soc Rev, 2017, 46: 915-1016

25 Liu M, Komatsu R, Cai X, et al. Horizontally orientated sticklike emitters: Enhancement of intrinsic out-coupling factor and electroluminescence performance. Chem Mater, 2017, 29: 8630-8636

26 Zhang Y, Zhang D, Tsuboi T, et al. Simultaneous enhancement of efficiency and stability of OLEDs with thermally activated delayed fluorescence materials by modifying carbazoles with peripheral groups. Sci China Chem, 2019, 62: 393-402

27 Jankus V, Data P, Graves D, et al. Highly efficient TADF OLEDs: How the emitter-host interaction controls both the excited state species and electrical properties of the devices to achieve near $100 \%$ triplet harvesting and high efficiency. Adv Funct Mater, 2014, 24: 6178-6186

28 Wang H, Xie L, Peng Q, et al. Novel thermally activated delayed fluorescence materials-thioxanthone derivatives and their applications for highly efficient OLEDs. Adv Mater, 2014, 26: 51985204

29 dos Santos PL, Ward JS, Congrave DG, et al. Triazatruxene: A rigid central donor unit for a D- $\mathrm{A}_{3}$ thermally activated delayed fluorescence material exhibiting sub-microsecond reverse intersystem crossing and unity quantum yield via multiple singlet-triplet state pairs. Adv Sci, 2018, 5: 1700989

30 Zhan L, Chen Z, Gong S, et al. A simple organic molecule realizing simultaneous TADF, RTP, AIE, and mechanoluminescence: Understanding the mechanism behind the multifunctional emitter. Angew Chem Int Ed, 2019, 58: 17651-17655

31 He Z, Cai X, Wang Z, et al. Reversible switching between normal and thermally activated delayed fluorescence towards "smart" and single compound white-light luminescence via controllable conformational distribution. Sci China Chem, 2018, 61: 677-686

32 Oh CS, Moon CK, Choi JM, et al. Relationship between molecular structure and dipole orientation of thermally activated delayed fluorescent emitters. Org Electron, 2017, 42: 337-342

33 Rajamalli P, Senthilkumar N, Huang PY, et al. New molecular design concurrently providing superior pure blue, thermally activated delayed fluorescence and optical out-coupling efficiencies. J Am Chem Soc, 2017, 139: 10948-10951

34 Komino T, Sagara Y, Tanaka H, et al. Electroluminescence from completely horizontally oriented dye molecules. Appl Phys Lett,
2016, 108: 241106

35 Ke K, Chen JX, Zhang M, et al. Improving performance of thermally activated delayed fluorescence emitter by extending its LUMO distribution. Sci China Mater, 2019, 62: 719-728

36 Furue R, Matsuo K, Ashikari Y, et al. Highly efficient red-orange delayed fluorescence emitters based on strong $\pi$-accepting dibenzophenazine and dibenzoquinoxaline cores: Toward a rational pure-red OLED design. Adv Opt Mater, 2018, 6: 1701147

37 Zeng W, Gong S, Zhong C, et al. Prediction of oscillator strength and transition dipole moments with the nuclear ensemble approach for thermally activated delayed fluorescence emitters. J Phys Chem C, 2019, 123: 10081-10086

38 Hu T, Han G, Tu Z, et al. Origin of high efficiencies for thermally activated delayed fluorescence organic light-emitting diodes: Atomistic insight into molecular orientation and torsional disorder. J Phys Chem C, 2018, 122: 27191-27197

39 Kim JH, Yun JH, Lee JY. Recent progress of highly efficient red and near-infrared thermally activated delayed fluorescent emitters. Adv Opt Mater, 2018, 6: 1800255

40 Zhang Y, Ran Q, Wang Q, et al. High-efficiency red organic lightemitting diodes with external quantum efficiency close to $30 \%$ based on a novel thermally activated delayed fluorescence emitter. Adv Mater, 2019, 31: 1902368

41 Wang S, Yan X, Cheng Z, et al. Highly efficient near-infrared delayed fluorescence organic light emitting diodes using a phenanthrene-based charge-transfer compound. Angew Chem Int Ed, 2015, 54: 13068-13072

Acknowledgements This work is dedicated to the Heroic City of Wuhan. Gong S, Zhong C and Yang C gratefully acknowledge the financial support from the National Natural Science Foundation of China (51873158, 51573141, 91833304 and 91433201), the National Key R\&D Program of China (2016YFB0401002), Shenzhen Science and Technolgy Program (KQTD20170330110107046 and JCYJ20190808151209557), the Key Technological Innovation Program of Hubei Province (2018AAA013), and the Natural Science Foundation for Distinguished Young Scholars of Hubei Province (2017CFA033). Wu CC acknowledges the support from the Ministry of Science and Technology of Taiwan (MOST 107-2221-E-002-160-MY3 and 108-2221-E-002-148MY3). Lee WK acknowledges the post-doctoral fellowship from the Ministry of Education (MOE) of Taiwan. The numerical calculations in this paper have been done on the supercomputing system in the Supercomputing Center of Wuhan University.

Author contributions Zeng W, Gong S and Yang C conceived the original idea for investigation. Zeng X, Huang YH, Gong S, Wu CC and Yang C wrote the manuscript. Zeng X, Yin X, Xiao X, Zhang Y, and Dong XQ synthesized the compounds. Zeng $X$ and Huang YH measured photophysical, thermal and electrochemical properties of the compounds. Huang $\mathrm{YH}$, Lee $\mathrm{WK}, \mathrm{Lu} \mathrm{CH}$, and Lee $\mathrm{CC}$ fabricated and characterized the devices. Gong S, Wu CC and Yang C supervised this research. Zhong $\mathrm{C}$ performed the quantum chemical calculations and molecular dynamics simulation. All authors discussed the progress of research and reviewed the manuscript.

Conflict of interest The authors declare no conflict of interest.

Supplementary information Experimental details and supporting data are available in the online version of the paper. 


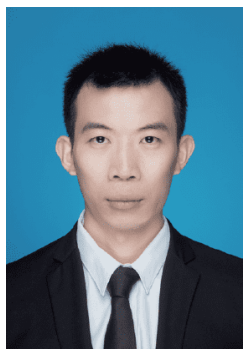

Xuan Zeng is a PhD student of Hubei Key Lab on Organic and Polymeric Optoelectronic Materials at Wuhan University. His research is focused on the optoelectronic materials and devices, mainly in the design, synthesis, and characterization of thermally activated delayed fluorescent materials with preferentially horizontal dipole orientation and high efficiency.

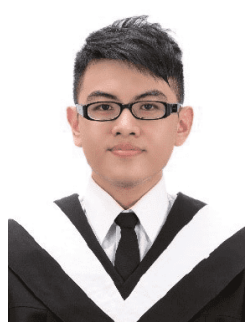

Yu-Hsin Huang received his BSc degree from the Department of Photonics, Sun Yat-San University (Kaohsiung) in 2015. Currently, he is in his $\mathrm{PhD}$ program in Graduate Institute of Electronics Engineering, Taiwan University. His research interest is in OLEDs, transparent conducting oxides and display technologies.

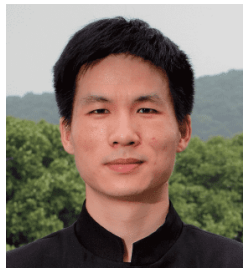

Shaolong Gong received his $\mathrm{BSc}$ and $\mathrm{PhD}$ from Wuhan University in 2007 and 2012, respectively. After working at the University of Toronto as a postdoctoral fellow, he joined the faculty of Wuhan University as an associate professor in 2014. His current research interests focus on the development of organic/polymeric optoelectronic materials and devices.

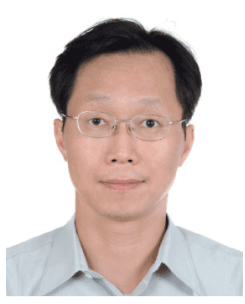

Chung-Chih Wu received his $\mathrm{PhD}$ degree in electrical engineering from Princeton University in 1997. He is currently the Micron Technology Chair Professor and Chairman of Electrical Engineering Department, Taiwan University. He has conducted researches and published widely in OLEDs, organic semiconductors and optoelectronics, oxide semiconductors and TFTs, and displays.

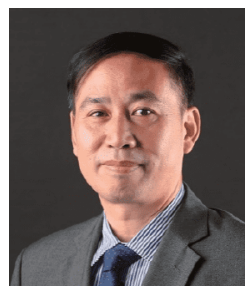

Chuluo Yang received his $\mathrm{PhD}$ degree in organic chemistry from Wuhan University in 1997. From 1999 to 2002, he was a postdoctoral fellow at the Hong Kong University of Science and Technology, University of New Orleans, and University of Rochester. From 2003 to 2018, he has been a full professor at Wuhan University. Since 2019, he has been a full professor at Shenzhen University. His research interests cover the synthesis, structure, property and device of organic/polymeric optoelectronic materials.

\section{具有完美水平取向的红光型热活化延迟荣光材料}

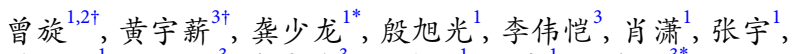
曾维轩 ${ }^{1}$, 吕承翰 ${ }^{3}$, 李章诚 $^{3}$, 董秀琴 ${ }^{1}, \mathrm{c}^{\text {地成 }}{ }^{1}$, 吴忠帜 ${ }^{*}$, 杨楚罗 ${ }^{1,2 *}$

摘要 如何实现发光材料跃迁偶极矩取向的调控一直是有机发光 二极管(OLEDs)领域的巨大挑战之一. 本文中, 我们基于双位点长 轴延伸策略, 设计合成了一种线型的热活化延迟苂光(TADF) 分子, PhNAI-PMSBA, 实现了对跃迁偶极矩取向的选择性调控. 由于 PhNAI-PMSBA具有显著的水平分子取向, 且其分子长轴与跃迁偶 极矩取向高度统一, PhNAI-PMSBA在掺杂发光薄膜中获得的跃迁 偶极矩水平取向度高达 $95 \%$ ，远高于各向同性发光分子 $67 \%$ 的跃迁 偶极矩水平取向度. 因此, 基于PhNAI-PMSBA的红光OLED的光耦 合输出效率可达 $43.2 \%$, 最大外量子效率达到 $22.3 \%$, 其CIE1931色 坐标位于 $(0.60,0.40)$. 